\title{
ANTIOXIDANT PROPERTIES OF RESVERATROL AND ITS PROTECTIVE EFFECTS IN NEURODEGENERATIVE DISEASES
}

\author{
Joanna GERSZON, Aleksandra RODACKA, Mieczysław PUCHAŁA
}

\author{
Department of Radiobiology, Faculty of Biology and Environmental Protection, \\ University of Łódz
}

DOI: $10.2478 /$ acb-2014-0006

\begin{abstract}
Summary: Resveratrol is a natural organic compound, polyphenol, produced naturally by some plants in response to several harmful factors such as attack by pathogens, UV radiation, or increased oxidative stress. Many experiments suggest that it triggers mechanisms that counteract aging-related effects and plays a role in insulin resistance as well. It also possesses beneficial properties such as anti-cancer, anti-inflammatory, blood-sugar-lowering and cardiovascular effects. It is supposed to exhibit an interesting activity in neuroprotection - mainly through activation of sirtuins and counteraction in forming peptide aggregates. Still research is needed to evaluate exactly how resveratrol protects neurons, and to develop new, potential, therapeutic drugs.
\end{abstract}

Key words: resveratrol, neuroprotection, neurodegenerative diseases, sirtuins, protein aggregates

List of abbreviations: A $\boldsymbol{\beta}$ - beta amyloid, ADAM 10 - protein belonging to the family of alpha-secretases, AKT - serine/threonine kinase Akt, AMPK - AMP-dependent kinase, ARE - the antioxidant response element, BDNF - brain derived neurotrophic factor, CaMKK $\boldsymbol{\beta}$ - calmodulin-dependent protein kinase kinase $\beta$, cAMP - adenosine 3',5'-cyclic monophosphate, COX1 - cyclooxygenase 1, DRP1 - dynamin-related protein, Epac1 - guanine nucleotide exchange factor, $\mathbf{F}_{2 \alpha}\left(\mathbf{8}\right.$-iso-PGF $\left.\mathbf{F}_{2 \alpha}\right)$ 8-iso-prostaglandin $\mathrm{F}_{2 \sigma}, \mathbf{G S K - 3 \beta - \beta}$ - glycogen synthase kinase 3, HD - Huntington's disease, HSF1 - heat shock factor, HSP-70 - heat shock protein, LDL - low density lipoproteins, MeCP2 - transcriptional protein, MFN1 - mitofusin 1, MFN2 - mitofusin 2, mPGES-1 - microsomal prostaglandin E synthase 1, MPTP-1 - methyl-4-phenyl-1,2,3,6-tetrahydropyridine, MsrA - methionine sulfoxide reductase, NEP - neprilysin, MyoD - myoblast determination protein 1, NF -kB - nuclear transcription factor, Nrf2 - nuclear factor 2, OH -1 - heme oxygenase 1, OPA1 - optic atrophy 1, PD - Parkinson's disease, PDE - phosphodiesterase cyclic nucleotides, PI3K - phosphatidylinositol 3-kinase, PGC$\mathbf{1 \alpha}$ - proliferator peroxisome-activated receptor gamma coactivator 1-alpha, $\mathbf{P G E}_{2}$ - prostaglandin $\mathrm{E}_{2}, \mathbf{R A R}$ - retinoic acid receptor $\beta, \mathbf{R N S}$ - reactive nitrogen species, $\mathbf{R O C K}$ - Rho-dependent kinase, ROS - reactive oxygen species, RSV - resveratrol, SIRT1 - sirtuin 1, SIRT3 - sirtuin 3, SOD - superoxide dismutase, TMS - 2,3',4,5' tetramethylstilbene, TORC1 - target-of-rapamycin complex 1, YY1 - transcription factor Yin Yang 1 


\section{INTRODUCTION}

Resveratrol (RSV, 3,5,4'- trihydroxy-trans-stilbene) is a phytoalexin produced by some plants in response to several harmful environmental factors, such as: UV radiation, attack by fungi, bacteria and viruses, as well as the effect of mechanical plants damage. This compound was first isolated by Michio Takaoka in 1939 from white hellebore root (Veratrum grandiflorum). The name resveratrol presumably comes from the fragments of words: res - the name of the compound, resorcinol, which is a derivative of resveratrol; -veratr - the name of the plant Veratrum and -ol - indicating the presence of hydroxyl groups [9]. This compound is present inter alia in the roots of giant knotweed (Polygonum cuspidatum), plant used in traditional Chinese and Japanese medicine, currently primary commercial source of pure resveratrol [8]. Resveratrol occurs naturally in approximately 72 species of plants belonging among others, to class Cyperaceae, Dipterocarpaceae, Vitaceae and Gnetaceae $[9,63]$. Red grapes, especially the dark variety (Vitis vinifera) are a rich source of resveratrol. It is also present in fruit: mulberry, black currant, blueberries, american lingonberries, strawberries, raspberries, apples and peanuts [37]. Intensive research efforts have been focused on the biological properties of the resveratrol since it has been associated with so-called "French paradox" [9]. Besides the beneficial effects on the cardiovascular system, resveratrol exerts also anti-inflammatory effects, inhibits the excessive fat accumulation in adipose tissue and inhibits the growth of cancer cells, by acting as an antiproliferative and proapoptotic agent [18]. Particularly important, due to the increasing number of people suffering from degenerative diseases of central nervous system, are the neuroprotective properties of RSV [37]. Currently it is estimated that more than 30 million people suffer from Alzheimer disease alone. Researchers estimate that by 2050 this number will increase 3 times if the development of new effective therapies to prevent the disease fails.

Due to the wide spectrum of effects, resveratrol is of a great interest to scientists. At the first conference in 2010 (Resveratrol $20101^{\text {st }}$ International Conference on Resveratrol and Health) there were formulated some very important conclusions and suggestions for further directions of studies concerning resveratrol. The overall conclusion was that available data are not sufficient to recommend the RSV for long-term administration to humans in doses higher than those taken with food. However, the data obtained from animal studies are so promising that further clinical studies on humans are recommended [84]. This review aims to present the results of some recent research concerning the role of resveratrol in the counteraction of neurodegenerative changes. 


\section{PHYSICAL PROPERTIES OF RESVERATROL}

Resveratrol $\left(\mathrm{C}_{14} \mathrm{H}_{12} \mathrm{O}_{3}\right)$ exists in two isomeric cis- and trans- forms (fig. 1). Cis-resveratrol is less common and it is very unstable. Exposure of the isomer trans- to the UV light results in conversion of trans- to cis- isomer [81, 85]. The literature data indicate that trans-resveratrol is biologically more active than cisisomer [81]. The molar mass of resveratrol is $228.25 \mathrm{~g} / \mathrm{mol}$, melting point is in the range of $253-255^{\circ} \mathrm{C}$. Resveratrol is well soluble in fat, ethanol $(50 \mathrm{mg} / \mathrm{ml})$ and DMSO $(16 \mathrm{mg} / \mathrm{ml})$. Its solubility in water is very low, approx. $3 \mathrm{mg} / 100 \mathrm{ml}$ (approx. $103 \mu \mathrm{M}$ ) and, according to the definition of the European Pharmacopoea $\mathrm{ia}$, it is considered to represent a compound practically insoluble in water. It also makes it poorly bioavailable to the human body [2]. Under laboratory conditions, using ultrasound ( 2 hours sonication $40 \mathrm{~W}$ at the temp. of $25-30^{\circ} \mathrm{C}$ in the dark) it is possible to get slightly higher solubility in water - up to $300 \mu \mathrm{M}$ [7]. In a cryse talline form both resveratrol and its glucoside derivative (piceid) are stable for up to about three months [31].

\section{MECHANISMS OF RESVERATROL'S ANTIOXIDANT ACTION IN BIOLOGICAL SYSTEMS}

Taking into account the antioxidant properties of resveratrol, there should be considered a few, closely related aspects of its action. Resveratrol is a very effective scavenger of reactive oxygen (ROS) and nitrogen (RNS) species as well as of secondary organic radicals formed as a result of the reaction of biomolecules with ROS and RNS [15]. Resveratrol increases the expression of certain enzymes responsible for maintaining the oxidation-reduction balance in a cell, such as: superoxide dismutase (SOD), catalase, heme oxygenase, glutathione peroxidase $[35,65]$. It also reduces activity of enzymes which play a dominant role in the production of ROS, such as xanthine oxidase [19]. Similarly to other polyphenols, it is an effective metal ions chelator and, thus, it counteracts creation of free radicals in e.g. the Fenton's reaction [35].

Resveratrol demonstrates an unusually strong ability to remove free radicals. This property is related to presence of three hydroxyl groups in positions 3, 4' and 5, as well as presence of aromatic rings and a double bond in the molecule (fig. 1) [10, 29]. Experimental studies confirmed that removal of hydroxyl groups or their replacement with $-\mathrm{OCH}_{3}$ groups results in a loss of antioxidant properties of the compound. 


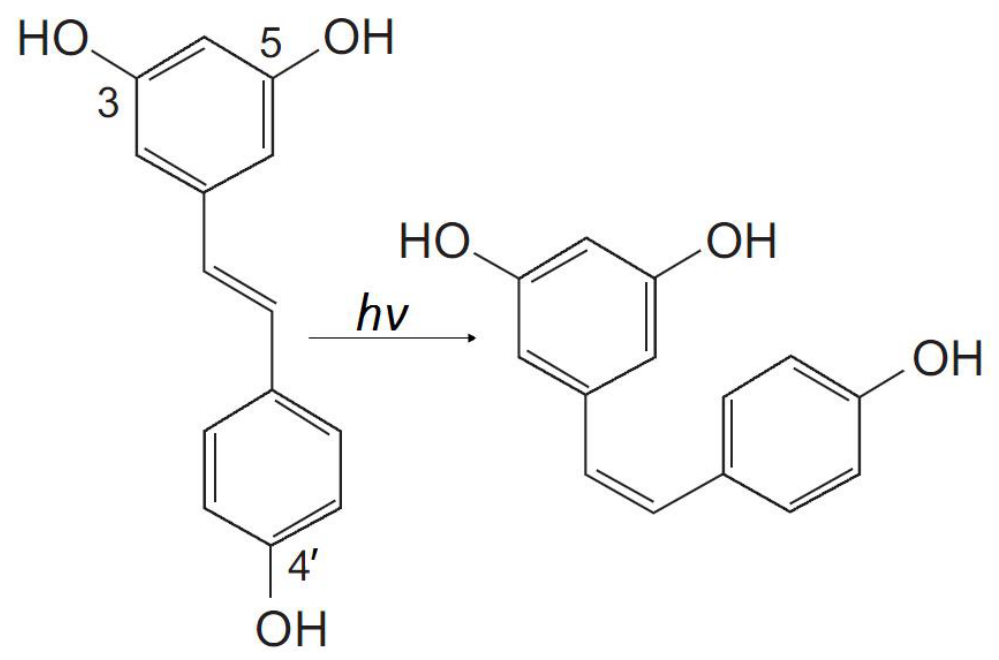

FIGURE 1. Chemical structures of trans- and cis-resveratrol

In addition, Caruso et al. [11] showed that the $\mathrm{OH}$ group at position 4' is much more reactive compared to the other two groups in positions 3 and 5. The effectiveness of resveratrol in scavenging free radicals is best reflected by high reaction rate constants reported in table 1.

TABLE 1. Rate constants for reaction of resveratrol with various radicals

\begin{tabular}{|c|c|c|}
\hline Reaction & pH & $\mathbf{k}\left[\mathbf{M}^{-1} \mathbf{s}^{-1}\right]$ \\
\hline $\mathrm{RSV}+{ }^{\cdot} \mathrm{OH}$ & 7 & $5 \times 10^{9}$ \\
\hline $\mathrm{RSV}+{ }^{\cdot} \mathrm{OH}$ & 10,5 & $6,9 \times 10^{9}$ \\
\hline $\mathrm{RSV}+{ }^{\cdot} \mathrm{OH}$ & 7,4 & $2,26 \times 10^{10} \quad[29]$ \\
\hline $\mathrm{RSV}+\mathrm{O}_{2} \cdot$ & 7 & $2 \times 10^{7}$ \\
\hline $\mathrm{RSV}+{ }^{\cdot} \mathrm{OOH}$ & 7,4 & $1,42 \times 10^{5}$ \\
\hline $\mathrm{RSV}+\mathrm{NO}$ & 10,5 & $1,2 \times 10^{8}$ \\
\hline $\mathrm{RSV}+\mathrm{NO}_{2}$ & 10,5 & $1-1,5 \times 10^{8}[44]$ \\
\hline
\end{tabular}


Rate constants of trans-resveratrol reaction with the hydroxyl radical $(\mathrm{pH}$ physiological, temp. $25^{\circ} \mathrm{C}$ ) are very high, $10^{10} \mathrm{M}^{-1} \mathrm{~s}^{-1}$. The constant calculated for the reaction of trans-resveratrol with superoxide $\left(10^{7} \mathrm{M}^{-1} \mathrm{~s}^{-1}\right)$ and the hydroperoxyl radical $(\bullet \mathrm{OOH})-\left(10^{5} \mathrm{M}^{-1} \mathrm{~s}^{-1}\right)[29,44]$ is much lower. It can be assumed that resveratrol is also an effective scavenger of the other radicals with a similar structure $(\bullet \mathrm{OOR})$, such as peroxyl radicals of lipids and proteins. In addition, resveratrol also effectively removes reactive nitrogen species [76, 88]. It has been shown that it directly reacts with peroxynitrite $\left(\mathrm{ONOO}^{-}\right)$. This makes it possible to prevent or reduce the nitrosylation of cysteine and tyrosine residues in proteins $[26,57,88]$. Sueishi et al. [76] demonstrated that RSV can neutralize nitric oxide. The rate of reaction of RSV with NO is higher than, e.g., the rate of the reaction of NO with catechin, myricetin, epicatechin, epigallocatechin gallate, kaempferol, but lower than the rate of the reaction of NO with trolox, uric acid and caffeine acid [76].

Resveratrol inhibits lipid peroxidation mainly by removing lipid peroxides produced in the membrane [78]. It prevents oxidation of polyunsaturated fatty acids present in low density lipoprotein, LDL [51]. Rocha et al. [66] showed that resveratrol given to rats on high-fat diet considerably reduced the level of oxidized LDL. Resveratrol can also protect the rats' heart against lipid peroxidation induced by the action of doxorubicin [20].

Antioxidant properties of resveratrol are also associated with activation of enzymes responsible for removal of reactive oxygen species generated in the body. The main enzymes activated in neuronal cells, as well as in other cells in the body are mitochondrial superoxide dismutase (SOD2) and catalase [74]. Such observations were reported both in in vitro and in vivo studies. It has been shown, inter alia, that the intraperitoneal administration of resveratrol to healthy rats results in an increased expression of endogenous antioxidant enzymes (superoxide dismutase and catalase) in the brain [54]. A similar effect of resveratrol was observed in mouse hippocampal cells (HT22) treated with high concentrations of glutamate, which caused an increased oxidative stress. It has been proved that resveratrol induces expression of mitochondrial superoxide dismutase by activation of the PI3K/AKT and GSK-3 $\beta$ - $\beta$-catenin signaling pathway [23]. An increase in mitochondrial superoxide dismutase expression was also observed in mouse myoblasts, $\mathrm{C} 2 \mathrm{C} 12$. In this case, RSV translocates to the nucleus where it activates sirtuin 1, which directly induces the expression of SOD2. It also worth citing Carrizzo et al. studies [8], carried out on a group of 59 patients with hypertension and dyslipidemia, which showed that resveratrol enhances the expression of mitochondrial superoxide dismutase by the mechanism dependent on the nuclear factor Nrf2 (Nuclear erythroid 2 - related factor). Beside dismutase and catalase, resveratrol also enhances expression of heme oxygenase-1 (HO-1). This effect was observed in macrophages, neuronal cells (HT22, PC12, astrocytes line C60) 
and human aortic smooth muscle cells [13, 32, 62]. Heme oxygenase-1 reduces cell damage under oxidative stress conditions induced by ischemia, inflammation, hypoxia and hyperoxia. Due to HO-1, free heme, which is cytotoxic and acts prooxidatively, is broken down in the body. Emerging after heme decomposition, biliverdin and bilirubin have potent antioxidant activity. In the central nervous system (CNS), heme oxygenase is a key defensive mechanism of cells exposed to oxidizing agents. It was found that resveratrol increases expression of inducible heme oxygenase by activation of the nuclear factor Nrf2 [13, 32, 62]. Under homeostasis, Nrf2 accumulates in the cytoplasm and forms a complex with the inhibitory protein Keap1. Keap1 functions as a sensor of oxidative stress and if an imbalance in oxidation-reduction occurs, Nrf2 is released from Nrf2 - Keap1 complex. During translocation of Nrf2 to the nucleus it associates with the antioxidant response elements (ARE) found in the promotor region of nuclear DNA. Activation of genes encoding enzymes of the second phase is taking place, such as glutathione S-transferase, the above- described heme oxygenase, oxidoreductase $\mathrm{NAD}(\mathrm{P}) \mathrm{H}$ : quinone [71].

Recent studies have shown that resveratrol increases expression of reductase methionine sulfoxide (MsrA) in human neuroblastoma SH-SY5Y cells [85]. Methionine sulfoxide reductase (MsrA) is one of the enzymes involved in protection of cells from damage caused by oxidative stress. Research has shown that overexpression of the MsrA in the dopaminergic cells prevents damage leading to death and reduces the level of protein aggregation induced by the action of neurotoxins, such as, e.g., rotenone [42].

As indicated at the beginning of this section, one of the mechanisms of antioxidant action of resveratrol is a reduction in activity of enzymes which play an important role in the production of ROS in the body. One of such enzymes is cyclooxygenase 1 (COX 1). It is an enzyme that catalyzes the first step in the synthesis of prostaglandins. It has been found that resveratrol inhibits cyclooxygenase 1 in the concentration-dependent manner [77]. These observations were confirmed in subsequent studies, including those conducted on rat microglial cells treated with lipopolysaccharide (LPS). It has been found that resveratrol significantly reduced activity of $\mathrm{COX} 1$, which did not result in the synthesis of prostaglandin $\left(\mathrm{PGE}_{2}\right)$ and the formation of 8-iso-prostaglandin F2 $\alpha$ (8-iso-PGF $\left.{ }_{2 \alpha}\right)$, factors involved in production of free radicals. Furthermore, it was observed that resveratrol in a dose-dependent manner reduces expression of microsomal synthase 1 (mPGES-1), an enzyme which takes part in one of the stages of $\mathrm{PGE}_{2}$ synthesis [5].

Both in vitro and in vivo studies have shown that resveratrol supresses the activity of xanthine oxidase and NADPH oxidase, the enzymes which are some of the main sources of superoxide anion production in the body $[69,74]$. 


\section{THE RESVERATROL'S ROLE IN COUNTERACTING AGGREGATION OF LOW MOLECULAR WEIGHT PEPTIDES AND PROTEINS INVOLVED IN NEURODEGENERATIVE PROCESSES}

Epidemiological studies indicate that moderate wine consumption significantly reduces the risk of developing Alzheimer's disease. Found in wine polyphenolic compounds, beside their strong antioxidant properties, may also directly prevent formation of aggregates of $\beta$-amyloid, alpha-synuclein, tau protein and/or reduce their toxicity [39]. In addition, polyphenols induce processes counteracting excessive accumulation of the above-mentioned proteins in a cell. Among the compounds found in large amounts in red wine (resveratrol, quercetin and catechin) only resveratrol significantly reduces the level of intracellular accumulation of amyloid $\beta$-peptide [45]. It might be an effect of various mechanisms. It has been proved that resveratrol increases activity of neprilysin (NEP), a proteolytic enzyme belonging to zinc metalloendopeptidases family [45]. This is an extremely important enzyme, degrading $\mathrm{A} \beta$ in vivo. Effective removal of amyloid peptide by NEP overexpression can be an important element of a new strategy for the therapeutic treatment of $\mathrm{AD}$ [60]. Resveratrol also activates the proteasome, whose activity is significantly reduced in the brain of patients with Alzheimer's disease [62]. Proteasome activation leads to an efficient degradation of $A \beta$ [62]. This process also prevents the excessive accumulation of modified proteins in cell [64]. Anti-amyloidogenic activity also showed three analogues of resveratrol: piceatannol (trans-3,3',4,5'-tetrahydroksystilben), trans-3,4',5-trimethylstilbene and TMS (2,3',4,5'-tetramethylstilbene). All tested derivatives decreased the level of A $\beta$ in cells but only TMS showed a high efficiency, comparable to resveratrol [45].

Studies conducted by Feng et al. [21] demonstrate that RSV is directly linked to $A \beta 42$ and in the concentration-dependent manner inhibits formation of $A \beta 42$ fibrils. The effectiveness of RSV in this process is very high, as added to A $\beta 42$ $(10 \mu \mathrm{M})$ at a concentration of $10 \mu \mathrm{M}$ or $100 \mu \mathrm{M}$ it inhibits formation of amyloid fibrils by, respectively, $50 \%$ and $90 \%$. Comparing the activity of other polyphenols (ginkgolides, catechins, curcumin) it has been shown that RSV has the strongest anti-amyloidogenic properties [21].

In the neurodegenerative diseases, aggregating proteins do not form one product but several conformers of varying toxicity and specific biochemical properties. Ladiwala et al. [39] studied the effects of resveratrol on individual products formation during aggregation of amyloid peptide, consisting of 42 amino acid residues (A 342 ). Among the different conformers, they pointed out the ones that had been transformed by resveratrol. These were: soluble oligomers, intermediates and fibrillar amyloid fibrils. They were converted to the alternative non-toxic insoluble products 
characterized by high molecular weight and lack of an ordered structure [39]. Inhibition of toxic conformers formation by resveratrol is associated with its structure. It was found that the two aromatic rings of resveratrol bind to $\beta$ structures present in significant quantities in the A $\beta 42$ oligomers, which can prevent the formation of fibrils and destabilize the existing ones (fig. 2). In contrast to the above-cited studies [21], the Tessier's group [39] found that resveratrol does not directly affect the structure of soluble low molecular weight $\mathrm{A} \beta$ monomers and non-toxic oligomers.

Another important observation regarding the neuroprotective action of resveratrol results from in vivo studies on mice which were fed for 45 days with food containing resveratrol. Even if resveratrol or its metabolites were not found in mouse brains, in certain areas of the encephalon much fewer amyloid plaques were formed. The greatest reduction was observed in the medial cortex (48\% reduction) in the striatum $(89 \%$ reduction) and in the hypothalamus ( $90 \%$ reduction). These changes occurred without detectable activation of SIRT1 and without changes associated with the processing of the amyloid precursor protein APP. Besides, a significant reduction in glutathione (21\%) and an increase in cysteine to $51 \%$ were reported in the brains. These results suggest that RSV induces an increased level of cysteine, which might be important in the protection and prevention of amyloid plaque formation [34].

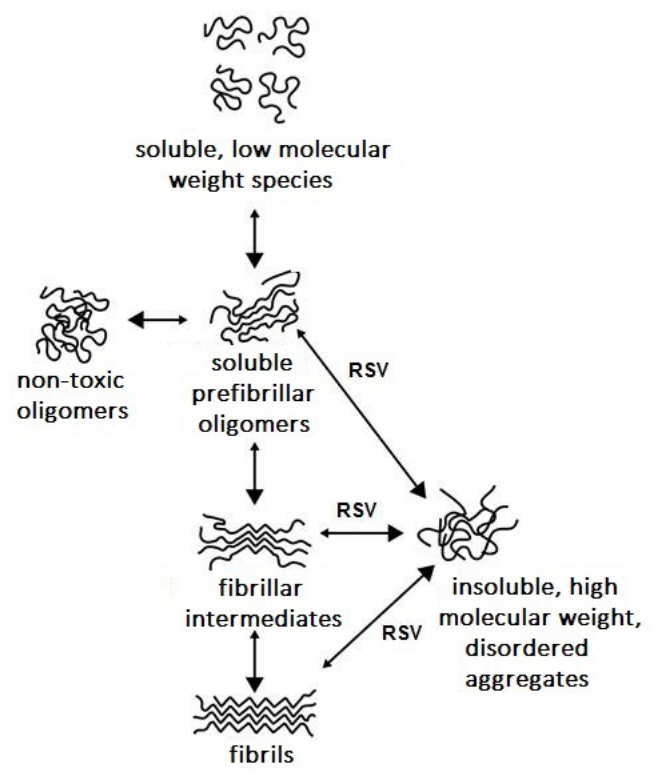

FIGURE 2. Pathways of formation for toxic and non-toxic, fibrillar oligomers. Resveratrol remodels conformers into non-toxic, high molecular weight structures 


\section{THE ROLE OF SIRTUINS IN NEURODEGENERATIVE DISEASES AND ROLE OF RESVERATROL IN THEIR ACTIVATION}

Due to the fact that the activity of sirtuins is important in neurodegenerative diseases, their role and participation of resveratrol in their activation were described in the following chapter.

Sirtuins belong to the family of $\mathrm{NAD}^{+}$-dependent histone deacetylases and are a highly conserved group of proteins occurring in both archaebacterial species and eukaryotes. In mammals seven homologs belonging to the Sir2 protein family (SIRT1 - SIRT7) were identified. They differ in their function and location in the cell (tab. 2) [4]. So far sirtuin 1 (SIRT1) has been the best known. Human SIRT1 is the largest protein of the sirutins family. Its molecular weight is $81.7 \mathrm{kDa}$ and it consists of 747 amino acid residues. In the central part of the molecule there is a globular catalytic $\mathrm{NAD}^{+}$binding domain (residues 273-517). On C-terminal and $\mathrm{N}$-terminal ends it contains two disorderd domains containing about 250 amino acid residues. Therefore, it has been included into the class of proteins known as inherently disordered, for which a separate database was created containing structural data (DisProt - Database for Protein Disorder). At the disordered ends there are signal sequences for the nuclear localization signal (NLS) and the nuclear export signal (NES) and numerous places that undergo post-translational modifications. SIRT1 localized in the nucleus mostly exhibits deacetylase activity [75]. Research carried out in recent years has considerably increased knowledge of the role of sirtuins in the body. Scientists hope to use these proteins for the protection against neurodegenerative processes. It has been shown that they maintain homeostasis of proteins directly involved in the formation of aggregates (eg. amyloid $\beta$, alpha-synuclein). They are also involved in enhancement of neuroplasn ticity, inhibition of inflammatory reaction and they ensure proper functioning of mitochondria. Moreover, they regulate epigenetic modifications [4].

Amyloid plaques are a characteristic feature of Alzheimer's disease and they are formed due to the accumulation of toxic peptides, consisting of 40-43 amino acid residues. Amyloidogenic peptides result from endoproteolytic cleavage of amyloid precursor protein (APP) by the beta and gamma secretases. Alpha- and gamma- secretases take part in an alternative process, in which non-amyloidogenic peptides are formed. Donmetz et al. [16] demonstrated that SIRT1 increases the activity of alpha-secretase by inhibition of ROCK kinase (Rho-dependent kinase) and further by deacetylation and activation of the receptor $\beta$ retinoic acid it increases transcription of the ADAM10 protein belonging to the alpha-secretase family (fig. 3) [16]. 
TABLE 2. Main characteristics of mammalian sirtuins

\begin{tabular}{|c|c|c|c|c|}
\hline Sirtuin & Cellular localization & $\begin{array}{l}\text { Main targets and } \\
\text { substrate }\end{array}$ & Physiological functions & References \\
\hline SIRT 1 & nucleus & $\begin{array}{c}\text { histone }(\mathrm{H} 1, \mathrm{H} 3, \mathrm{H} 4) \text { and } \\
\text { nonhistone proteins, } \\
\text { including FOXO, p53, } \\
\text { Ku70, receptory PPAR, } \\
\text { PGC-1 } \alpha, \text { NFкB }\end{array}$ & $\begin{array}{l}\text { regulation of metabolism } \\
\text { and cell survival, stress } \\
\text { response control }\end{array}$ & [6] \\
\hline SIRT 2 & cytoplasm, nucleus & $\begin{array}{l}\alpha \text {-tubulin, } \\
\text { histone H4 }\end{array}$ & $\begin{array}{l}\text { regulation of microtubule } \\
\text { stability, heterochroma- } \\
\text { tin formation, cell cycle } \\
\text { regulation }\end{array}$ & {$[53]$} \\
\hline SIRT 3 & mitochondria & $\begin{array}{l}\text { acylo-CoA } \\
\text { synthetase }\end{array}$ & $\begin{array}{c}\text { activation of mitochondrial } \\
\text { biogenesis, thermogenesis } \\
\text { regulation }\end{array}$ & {$[25]$} \\
\hline SIRT 4 & mitochondria & glutamate dehydrogenase & $\begin{array}{l}\text { downregulation of insulin } \\
\text { secretion }\end{array}$ & {$[53]$} \\
\hline SIRT 5 & mitochondria & $\begin{array}{l}\text { carbamoyl phosphate } \\
\text { synthetase } 1\end{array}$ & $\begin{array}{c}\text { regulation of the urea cycle, } \\
\text { ammonia detoxification }\end{array}$ & {$[55]$} \\
\hline SIRT 6 & $\begin{array}{c}\text { nucleus (associated } \\
\text { with heterochromatin) }\end{array}$ & unknown DNA pol $\beta$ & DNA repair control & [89] \\
\hline SIRT 7 & $\begin{array}{c}\text { nucleus (concentrated } \\
\text { in nucleoli) }\end{array}$ & RNA polymerase 1 & $\begin{array}{l}\text { regulation of rRNA synthe- } \\
\text { sis and ribosome production }\end{array}$ & [80] \\
\hline
\end{tabular}

Degenerative diseases called tauopaties (eg. Alzheimer's disease, corticobasal degeneration, dementia linked to lateral amyotrophic sclerosis and parkinsonism) are associated with the pathology of protein tau - associated with microtubules (Microtubule Associated Protein Tau, MAPT). In tauopaties, changes of tau protein depend on the type of disease. Alzheimer disease involves hyperphosphorylation, abnormal and excessive acetylation and increased accumulation of neurofibrillary tangles (NFT). in The number of neurofibrillary tangles in the brain of Alzheimer patients correlates inversely with the level of SIRT1 [52]. This relationship suggests that the increased accumulation of tau protein is associated with the low deacetylase activity of SIRT1 [33]. Appropriate regulation of acetylation/ deacetylation processes of tau protein may form the basis for new therapeutic approaches in treatment of tauopaties. Many studies indicate that resveratrol or its derivatives may be activators of SIRT1 [51].

In mammals, unnecessary and damaged proteins, e.g. unfolding, oxidatively modified or aggregated ones are removed by proteasome or in the process of autophagy by autophagosomes and lysosomes. The impaired autophagy process and 
the ubiquitin/proteasome pathway can cause premature aging and contribute to the development of neurodegenerative diseases such as Alzheimer's, Parkinson's and Huntington's disease. In proteasomes, peptides and proteins which have been previously attached to ubiquitin, are degradated. Both acetylation and ubiquitination occur on lysine residues, so acetylation often competes with polyubiquitination [52]. As a result of the increased acetylation, degradation of proteins by proteasomes is significantly reduced. Thus, reduced activity of SIRT1 results in protein hyperacetylation, which prevents polyubiquitination and degradation (fig. 3). An example of a protein that is over- acetylated with the reduced activity of SIRT1 is tau protein [52]. In the process of autophagy, damaged and aggregated proteins,

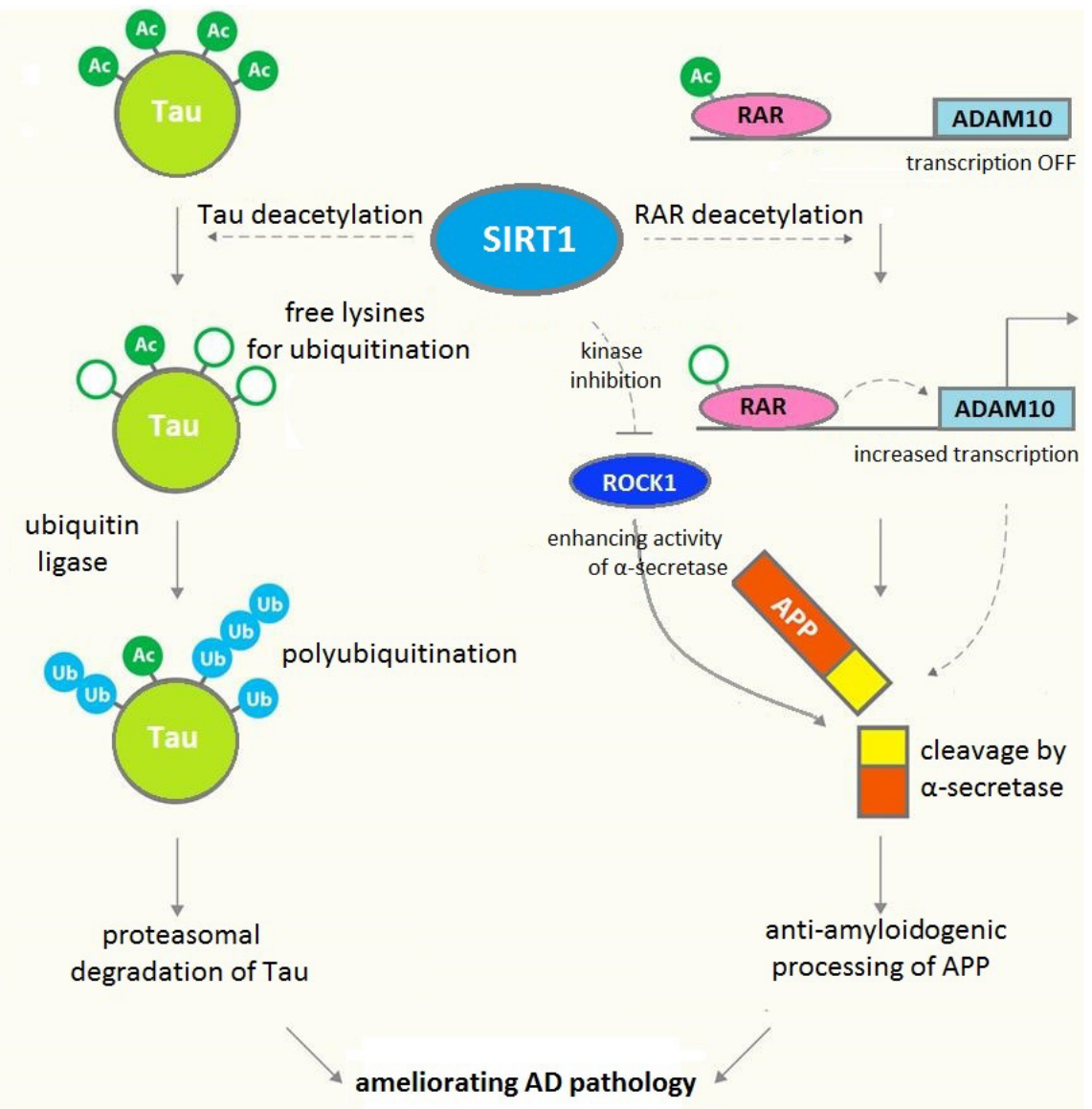

FIGURE 3. Protective mechanism of SIRT1 in Alzheimer disease. SIRT1 deacetylates tau protein, leading to increased tau polyubiquitination. SIRT1 enhances acitivity of alpha-secretases by reducing ROCK1 - kinase which suppresses alpha-secretase. It also deacetylates and induces activation of retinoic acid receptor (RAR) $\beta$, which enhances transcription of ADAM10 - a component of alpha-secretase [51] 
bacteria and viruses and malfunctioning organelles are removed. This process is stimulated, among other, by resveratrol. The influence of resveratrol is connected with activation of SIRT1, which directly affects the process of autophagy by deacetylation of protein components forming autophagosome. Furthermore, the deacetylation of transcription factor FOXO family (Forkhead transcription factor O) induces expression of proteins involved in autophagy [56]. Efficient processes of protein degradation play an important role in maintaining the normal function of all cells, especially long living neurons.

During the studies on human neuroblastoma SK-N-BE cell line it was observed that SIRT1, activated by resveratrol, protects cells from the toxic effect of alpha-synuclein [86]. One of the mechanisms that reduce alpha-synuclein aggregation in a cell is deacetylation of heat shock factor-1 (HSF1) by SIRT1 [86]. Deacetylated HSF-1 activates expression of heat shock protein, HSP-70, which increases resistance of cells to stress and maintains the proteins in the cell homeostasis (fig. 4) $[17,86]$.

The essential feature of neurodegenerative diseases is a progressive and irreversible reduction of synaptic plasticity which, in turn, leads to impairment of memory and learning abilities. Sirtuin 1 participates in maintenance of neuroplasticity by regulating the expression of small RNAs - miR-134. Normally, SIRT1 forms a complex with the transcription factor YY1, suppressing the expression of miR-134 and thereby increasing expression of the neurotrophic factor, BDNF (Brain-derived neurotrophic factor). BDNF increases the number of dendritic spines, neuronal connections and improves memory function (fig. 4). Anoth-
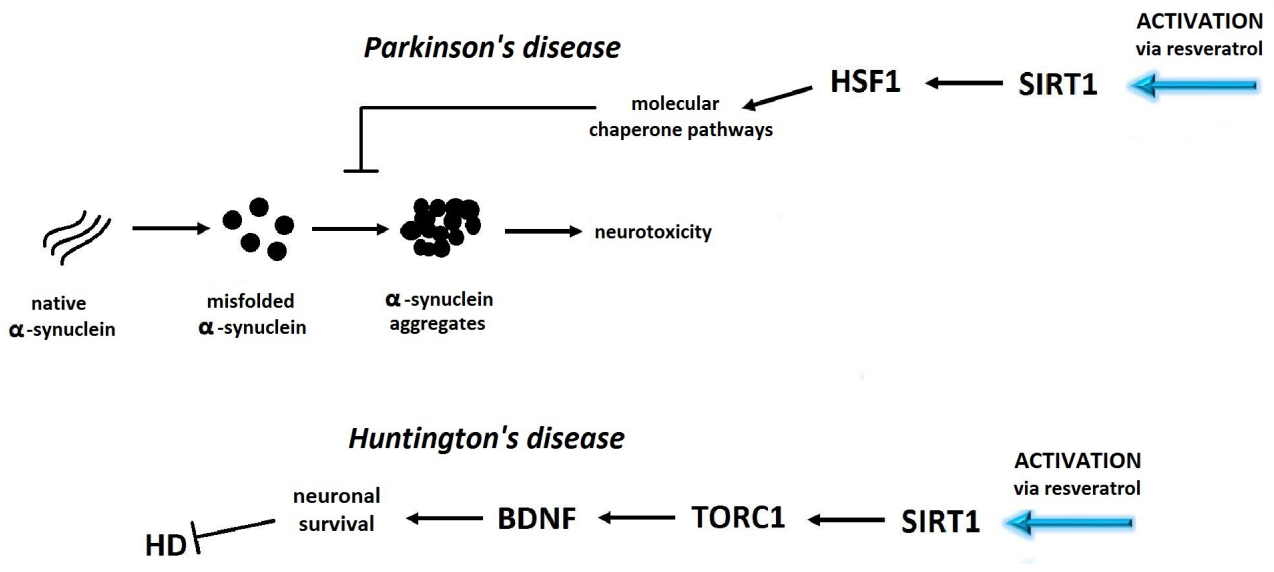

FIGURE 4. The role of SIRT1 in Parkinson's and Huntington's diseases. In PD models, SIRT1 leads to heat shock factor 1 (HSF1) deacetylation and, thus, results in an increased expression of heat shock protein HSP-70, thereby preventing alpha-synuclein aggregation. In HD, SIRT1 protects neurons by activating target of rapamycin complex 1 (TORC1) and brain-derived neurotrophic factor (BDNF) [17] 
er mechanism which mediates the regulation of BDNF by SIRT1 involves the deacetylation of $\mathrm{MeCP} 2$ protein (Methyl - $\mathrm{CpG}$-binding protein 2), which results in an increased transcription of BDNF in the hippocampus [24].

Peroxisome proliferator-activated receptor-gamma coactivator 1 alpha (PGC$1 \alpha)$ plays a key role in the regulation of cell metabolism, stimulation of mitochone drial biogenesis and oxidative phosphorylation. Additionally, it is a factor which determines the antioxidant cellular response by inducing expression of mitochondrial superoxide dismutase and glutathione peroxidase [46]. Studies conducted in mice lacking the gene encoding PGC- $1 \alpha$ showed that they are much more sensitive to neuronal cell damage triggered by MPTP (1-methyl-4-phenyl-1,2,3,6-tetrahydropyridinyl) and kainate. In Huntington's disease the mutated huntingtin inhibits expression of gene encoding PGC- $1 \alpha$. It has been shown that activation of PGC-1 $\alpha$ by SIRT1 attenuates the cytotoxic activity of mutant huntingtin and improves the function of mitochondria. Interaction of SIRT1 with PGC-1 $\alpha$ also affects in the maintenance of an appropriate energy equilibrium [14].

In many neurodegenerative diseases chronic, persistent inflammatory conditions are observed. A significant role in these processes is played by nuclear transcription factor $\mathrm{NF}-\kappa \mathrm{B}$, which regulates the immune response and activates expression of genes responsible for development of inflammation [44]. Degeneration and neuronal cell death due to inflammation, caused by activation of NF- $\mathrm{KB}$, is considered to be one of the elements of pathogenesis of Alzheimer's disease. It has been shown that SIRT1 and its activators, such as resveratrol and its derivatives, possess anti-inflammatory properties. Action of sirtuin in this case is exerted by inactivation of $\mathrm{NF}-\kappa \mathrm{B}$, which is a result of deacetylation of lysine at position 310 of p65 subunit of $N F-\kappa B$. Studies on mice have demonstrated that activity of NF- $\kappa B$ in the hypothalamus increases with age. Lifespan of the examined mice is prolonged by inhibition of NF- $\mathrm{KB}$. It has been observed that increased expression of SIRT1 or diet enriched with resveratrol significantly reduced neuronal loss caused by chronic inflammatory conditions. An increased expression of SIRT1 also significant ly decreases activity of NF- $\mathrm{KB}$ induced by the action of $\mathrm{A} \beta$ [17].

Due to the high energy requirements in the nerve cells a special role is played by mitochondria. These organelles produce energy but also are a major source of reactive oxygen species. It has been found that any disorder of the processes taking place in the mitochondria can be the beginning of neurodegenerative processes. Sirtuin 3 is of particular importance in maintenance of homeostasis in mitochondria [36]. It is located in the matrix as well as in the inner mitochondrial membrane. Under oxidative-stress conditions it can translocate to the nucleus. Expression of SIRT3 is the highest in metabolically active tissues and organs such as brain, heart, liver, brown adipose tissue and skeletal muscle [36]. SIRT3 participates in deacetylation and activation of several mitochondrial enzymes involved, among other, in $\beta$-oxidation of fatty acids, amino acid metabolism, transport of chain electrons and exhibits antioxidant activity (e.g. 
manganese superoxide dismutase and isocitrate dehydrogenase 2) [61]. Additionally, sirtuin 3 inhibits components of the mitochondrial permeability transition pore, such as cyclophilin D [36]. Mitochondria are dynamic organelles because they are constantly dividing, translocating, changing their size and shape. The balance between their divisions and fusion is crucial to functioning and survival of neuronal cells. The fragmentation of the mitochondria is controlled by the dynamin related protein 1 (DRP1) while the fusion takes place with participation of optic atrophy 1 proteins (OPA1), mitofusin 1 (MFN1), mitofusin 2 (MFN2) [36]. Preliminary studies have shown that higher activity of SIRT1 and SIRT3 increases metabolism by activating the fusion and stops divisions of mitochondria. In fruit flies and yeast after treatment with sirtuin's activating compounds, such as resveratrol or $\mathrm{NAD}^{+}$, increased mitochondrial fusion processes were observed. Consequently, this led to longer life of the specimens. Further studies need to be conducted to determine whether similar mechanisms are also found in mammals [36].

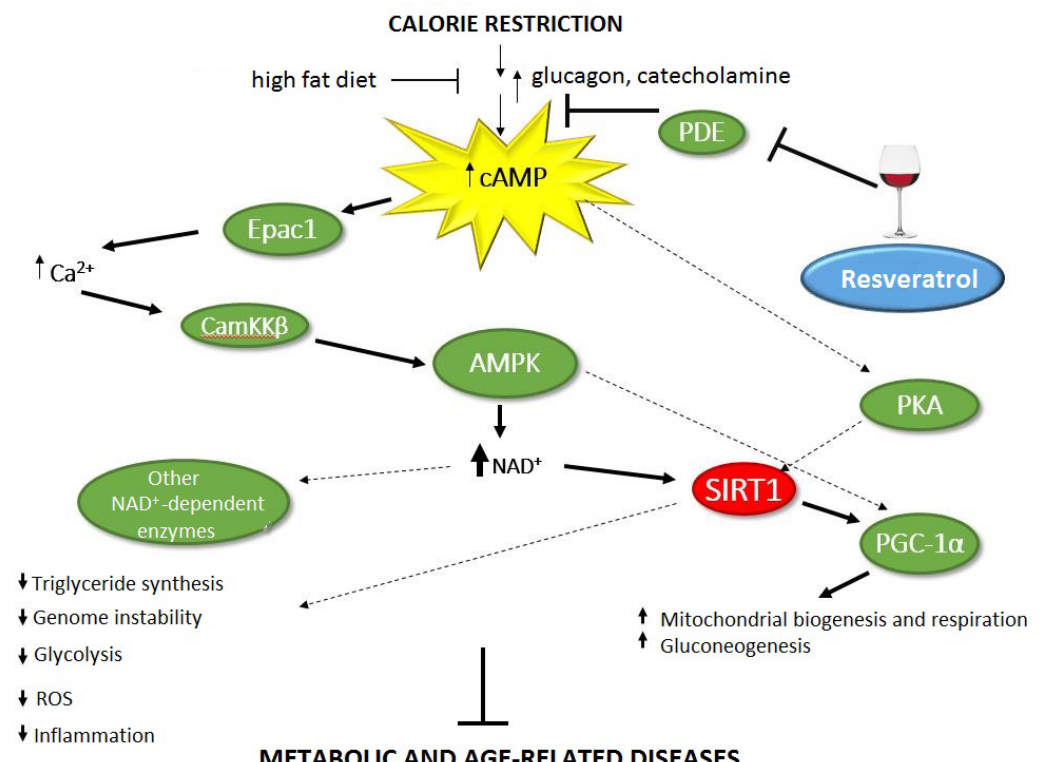

FIGURE 5. Mechanism of SIRT1 activation by resveratrol. The effect of resveratrol is similar to effects observed upon low caloric diet, it also leads to increase in cAMP. Resveratrol inhibits PDEs (phosphodiesterase), leading to increased cAMP (cyclic AMP) levels, Epac1 (cAMP-regulated guanine nucleotide exchange factor 1) activation, elevated intracellular calcium, and AMPK activation. Downstream of AMPK, an increase in NAD ${ }^{+}$levels leads to SIRT1 activation, which promotes beneficial metabolic changes primarily through deacetylation and activation of PGC- $1 \alpha$. Dashed arrows indicate the previously reported molecular pathway, showing that protein kinase A (PKA) phosphorylates and activates SIRT1. Increased cAMP levels activate PKA. Black arrows indicate the pathway proposed by Park et al. [58] 
In mammals, including primates, it was observed that a low-calorie diet similarly to the regular consumption of RSV repeatedly delayed the incidence of diseases such as atherosclerosis, cardiovascular disease, type 2 diabetes, cancer and neurodegenerative diseases. In both cases, some proteins, which are crucial in maintenance of homestasis, are activated. As described above, the primary mechanism of resveratrol's action in cell is activation of sirtuin $1[58,80]$. Despite many studies, this mechanism is still controversial. Some have questioned the ability of resveratrol to directly activate SIRT1 [58]. On the basis of numerous studies it was demonstrated unequivocally that resveratrol indirectly activates SIRT1 $[6,58,80]$. Park et al. [59] demonstrated that resveratrol directly inhibits activity of cyclic nucleotides phosphodiesterase (PDE), which leads to an increase in 3',5'-cyclic adenosine monophosphate (cAMP), activation of the exchange guanine nucleotide Epac 1 and elevation of intracellular calcium CaMKK $\beta$ controlling kinase activity (Calcium/Calmodulin - dependent Protein Kinase Kinase). CaMKK $\beta$ kinase by phosphorylating AMPK activates it, consequently it results in the inhibition of cholesterol synthesis pathways of fatty acids, insulin secretion and an increase in the level of $\mathrm{NAD}^{+}$which leads to activation of SIRT1 (fig. 5) [59]. Another mechanism taken into consideration is the phosphorylation and activation of SIRT1 by protein kinase PKA, whose activation is promoted by an increase cAMP levels (fig. 5) [59].

\section{SUMMARY}

Resveratrol is one of few naturally occurring compounds with such a wide health promoting spectrum of activity. The results obtained on the basis of numerous in vitro studies encourage scientists to continue investigations on animals, followed by clinical trials on humans. Particularly noteworthy is participation of resveratrol in activation of longevity enzymes, sirtuins. It was established that these enzymes have neuroprotective properties. Appropriate regulation of their catalytic activity could potentially be used in treatment of age-related disorders. Besides, it has been shown that resveratrol, by directly affecting proteins and peptides involved in neurodegenerative diseases, counteracts their toxicity and inhibits formation of toxic protein aggregates.

\section{ACKNOWLEDGEMENTS}

This study was supported by The National Science Centre (grant no. 2012/05/B/ NZ1/00701) 


\section{REFERENCES}

[1] Albani D, Polito L, Batelli S, De Mauro S, Fracasso C, Martelli G et al. The SirT1 activator resveratrol protects SK-N-BE cells from oxidative stress and against toxicity caused by alpha-synuclein or amyloid-beta(1-42)peptide. J. Neurochem. 2009; 110: 1445-1456.

[2] Amri A, Chaumeil JC, Sfar S, Charrueau C. Administration of resveratrol: What formulation solutions to bioavailability limitations? J Control Release. 2012; 10; 158(2): 182-193.

[3] Ashu J And Flint Beal M. Mitochondrial Dysfunction in Neurodegenerative Diseases. J Pharmacol Exp Ther. 2012; 342(3): 619-630.

[4] Balcerczyk A, Pirola L. Therapeutic potential of activators and inhibitors of sirtuins. BioFactors. 2010; 36(5): 383-393.

[5] Candelario-Jalil E, Slawik H, Ridelis I, Waschbischa, Akundi RS, Hull M, Fiebich BL. Regional distribution of the prostaglandin E2 receptor EP1 in the rat brain: accumulation in Purkinje cells of the cerebellum. Journal of Molecular Neuroscience. 2005; 27(3): 303-310.

[6] Canto C, Auwerx J. Caloric restriction, SIRT1 and longevity. Trends Endocrinol Metab. 2009; 7: 325-331.

[7] Camont L, Cottart CH, Rhayem Y, Nivet-Antoine V, Djelidi R, Collin F, Beaudeux JL, BonneFONT-RousSELOT D. Simple spectrophotometric assessment of the trans-/cis-resveratrol ratio in aqueous solutions. Anal Chim Acta. 2009; 634(1): 121-128.

[8] Carrizzo A, Forte M, Damato A, Trimarco V, Salzano F, Bartolo M, Maciag A, Puca AA, VecCHIONE C. Antioxidant effects of resveratrol in cardiovascular, cerebral and metabolic diseases. Food Chem Toxicol. 2013; 61: 215-226.

[9] Catalgol B, Batirel S, Taga Y, Ozer NK. Resveratrol: French paradox revisited. Front Pharmacol. 2012; 3: 141.

[10] Cao H, Pan X, Li C, Zhou C, Deng F, Li T. Density functional theory calculations for resveratrol. Bioorg Med Chem Lett. 2003; 13(11): 1869-1871.

[11] Caruso F, Tanski J, Villegas-Estrada A, Rossi M. Structural basis for antioxidant activity of trans-resveratrol: ab initio calculations and crystal and molecular structure. J Agric Food Chem. 2004; 52(24): 7279-7285.

[12] Chen J, Zhou Y, Mueller-Steiner S, Chen LF, Kwon H, Yi S. SIRT1 protects against microglia-dependent amyloid-beta toxicity through inhibiting NF-\{kappa\}B signaling. J. Biol. Chem. 2005; 280: 40364-40374.

[13] Chen CY, JANG JH, Li MH, Surh YJ. Resveratrol upregulates heme oxygenase-1 expression via activation of NF-E2-related factor 2 in PC12 cells. Biochem Biophys Res Commun. 2005; 331(4): 993-1000.

[14] Clark J, Silvaggi JM, Kiselak T, Zheng K, Clore El, Dai Y, Bass CE, Simon DK. Pgc-1 $\alpha$ overexpression downregulates Pitx3 and increases susceptibility to MPTP toxicity associated with decreased Bdnf. PLoS One. 2012; 7(11): e48925.

[15] Cordova-Gomez M, Galano A, Raul J, Alvarez-Idaboy JR. Piceatannol, a better peroxyl radical scavenger than resveratrol. RSC Advances. 2013; 3: 20209-20218.

[16] Donmez G, Wang D, Cohen DE, Guarente L. SIRT1 suppresses beta-amyloid production by activating the alpha-secretase gene ADAM10. Cell. 2010; 142: 320-332.

[17] Donmez G, QuTeIRo TF. SIRT1 and SIRT2: emerging targets in neurodegeneration. EMBO Mol. Med. 2013; 5: 344-352.

[18] Delmas D, Aires V, Limagne E, Dutatarte P, Mazue F, Ghiringhelli F, Latruffe N. Transport, stability, and biological activity of resveratrol. Ann N Y Acad Sci. 2011; 1215: 48-59.

[19] Delmas D, Jannin B, Latruffe N. Resveratrol: natural properties against atherosclerosis, associated pro-inflammatory effects and aging. Molecular Nutrition \& Food Research. 2005, 49(5): 377-395. 
[20] Dudka J, Gieroba R, Korga A, Burdan F, Matysiak W, Jodlowska-Jedrych B, Mandziuk S, Korobowicz E, Murias M. Different Effects of Resveratrol on Dose-Related Doxorubicin-Induced Heart and Liver Toxicity. Evidence-Based Complementary and Alternative Medicine. 2012; Article ID 60618: 10.

[21] Feng Y, Wang XP, Yang SG, Wang YJ, Zhang X, Dua XT, Suna XX, Zhao M, Huang L, Liu RT. Resveratrol inhibits beta-amyloid oligomeric cytotoxicity but does not prevent oligomer formation. NeuroToxicology. 2009; 30(6): 986-995.

[22] Franco SS, De Falco L, Ghaffari S, Brugnara C, Sinclair Da, Matte A, Iolascon A, Mohandas N, Bertoldi M, An X, Siciliano A, Rimmele P, Cappellini MD, Michan S, Zoratti E, Janin A, De FranCESCHI L. Resveratrol accelerates erythroid maturation by activation of FOXO3 and ameliorates anemia in beta-thalassemic mice. Haematologica. 2014; 99(2): 267-275.

[23] FunuI M, Yamabe N, Kang KS, Zhu BT. Growth-stimulatory effect of resveratrol in human cancer cells. Mol Carcinog. 2010; 49(8): 750-759.

[24] Gao J, Wang WY, Mao YW, Graff J, Guan JS, Pan L. A novel pathway regulates memory and plasticity via SIRT1 and miR-134. Nature. 2010; 466: 1105-1109.

[25] Hirschey MD, Shimazu T, Goetzman E, Jing E, Schwer B, Lombard DB, Grueter CA, Harris C, Biddinger S, Ilkayeva OR, Stevens RD, Li Y, Saha AK, Ruderman NB, Bain JR, Newgard CB, Farese RV JR, Alt FW, KAHN CR, Verdin E. SIRT3 regulates mitochondrial fatty-acid oxidation by reversible enzyme deacetylation. Nature. 2010; 464(7285): 121-125.

[26] Holthoff JH, Wooduing KA, Doerge DR, Burns ST, Hinson JA, Mayeux PR. Resveratrol, a dietary polyphenolic phytoalexin, is a functional scavenger of peroxynitrite. Biochem Pharmacol. 2010; 80(8): 1260-1265.

[27] Hurst WJ, Glinski JA, Miller KB, Apgar J, Davey MH, Stuart DA. Survey of the trans-resveratrol and trans-piceid content of cocoa-containing and chocolate products. J Agric Food Chem. 2008; 24: 56(18): 8374-8378.

[28] Hussein Mohammed A. A Convenient Mechanism for the Free Radical Scavenging Activity of Resveratrol, International Journal of Phytomedicine. 2011; 3: 459-469.

[29] Iuga C, Alvarez-Idaboy JR, Russo N. Antioxidant activity of trans-resveratrol toward hydroxyl and hydroperoxyl radicals: a quantum chemical and computational kinetics study. J Org Chem. 2012; 77(8): 3868-3877.

[30] Iwahara T, Bonasio R, Narendra V, Reinberg D. SIRT3 functions in the nucleus in the control of stress-related gene expression. Mol.Cell.Biol. 2012; 32: 5022-5034.

[31] Jensen JS, Wertz CF, O`NeILl VA. Preformulation stability of trans-resveratrol and trans-resveratrol glucoside (Piceid). J Agric Food Chem. 2010; 58(3): 1685-1690.

[32] Juan ME, Gonzalez-Pons E, Munuera T, Ballester J, Rodriguez-Gil Je, Planas JM. Trans-Resveratrol, a natural antioxidant from grapes, increases sperm output in healthy rats. J Nutr. 2005; 135(4): 757-760.

[33] Julien C, Tremblay C, Emond V, Lebbadi M, Salem N JR., Bennett DA. Sirtuin 1 reduction parallels the accumulation of tau in Alzheimer disease. J. Neuropathol. Exp. Neurol. 2009; 68: 48-58.

[34] Karuppagounder SS, Pinto JT, Xu H, Chen HL, Beal MF, Gibson GE. Dietary supplementation with resveratrol reduces plaque pathology in a transgenic model of Alzheimer's disease. Neurochem Int. 2009; 54(2): 111-118.

[35] Kavas GO, Ayral PA, Elhan AH. The Effects of Resveratrol on Oxidant/Antioxidant Systems and Their Cofactors in Rats. Adv Clin Exp Med. 2013; 22(2): 151-155.

[36] Kincaidand B, Bossy-Wetzel. Forever young: SIRT3 a shield against mitochondrial melt down, aging, and neurodegeneration. Frontiers in aging neurodegenearation. Front Aging Neurosci. 2013; 5: 48 .

[37] Kopeć A, Piątrowska E, Leszczyńska T, Bieżanowska-Kopeć R. Health-promoting affects of resveratrol [in Polish]. ŻYWNOŚĆ. Nauka. Technologia. Jakość. 2011; 5(78): 5-15. 
[38] Krstic D, Knuesel I. Deciphering the mechanism underlying late-onset Alzheimer disease. Nat. Rev. Neurol. 2013; 9: 25-34.

[39] Ladiwala AR, Lin JC, Bale SS, Marcelino-Cruz AM, Bhattacharya M, Dordcik JS, Tessier PM. Resveratrol selectively remodels soluble oligomers and fibrils of amyloid Abeta into off-pathway conformers. J Biol Chem. 2010; 285(31): 24228-24237.

[40] Li Y, CAO Z, ZHU H. Upregulation of endogenous antioxidants and phase 2 enzymes by the red wine polyphenol, resveratrol in cultured aortic smooth muscle cells leads to cytoprotection against oxidative and electrophilic stress. Pharmacol. Res. 2006; 53: 6-15.

[41] Li F, Gong Q, Dong H, Shi J. Resveratrol, A Neuroprotective Supplement for Alzheimer's Disease. Curr Pharm Des. 2012; 18(1): 27-33.

[42] Lin TK, Chen SD, Chuang YC, Lin HY, Huang CR, Chuang JH, Wang PW, Huang SH, Tiao MM, Chen JB, Liou CW. Resveratrol Partially Prevents Rotenone-Induced Neurotoxicity in Dopaminergic SH-SY5Y Cells through Induction of Heme Oxygenase-1 Dependent Autophagy. Int J Mol Sci. 2014; 15(1): 1625-1646.

[43] Ludolph AC, Kassubek J, Landwehrmeyer BG, Mandelkow E, Mandelkow EM, Burn DJ. Tauopathies with parkinsonism: clinical spectrum, neuropathologic basis, biological markers, and treatment options. Eur.J.Neurol. 2009; 16: 297-309.

[44] Mahal Hs, MukherJee. Scavenging of reactive oxygen radicals by resveratrol: antioxidant effect. Research on Chemical Intermediates. 2006; 32(1): 59-71.

[45] Marabaud P, Zhao H, Davies P. Resveratrol promotes clearance of Alzheimer's disease amyloid-beta peptides. J Biol Chem. 2005; 280(45): 37377-37382.

[46] Martin OJ, Lai L, Soundarapandian MM, Leone TC, Zorzano A, Keller MP, Attie AD Muoio DM, Kelly DP. A Role for Peroxisome Proliferator-Activated Receptor $\gamma$ Coactivator-1 in the Control of Mitochondrial Dynamics During Postnatal Cardiac Growth. Circ Res. 2014; 114(4): 626-636.

[47] Mccall CE, Elgazzar M, Liu T, Vachharajani V, Yoza B. Epigenetics, bioenergetics, and microRna coordinate gene-specific reprograming during acute systemic inflammation. J. Leukoc.Biol. 2011; 90: 439-446.

[48] Medzhitov R, Horng T. Transcriptional control of the inflammatory response. Nat.Rev.Immunol. 2009; 9: 692-703.

[49] Michan S, Sinclair. Sirtuins in mammals: insights into their biological function. Biochem J. 2007; 404(1): 1-13.

[50] Mikstacka R, Ignatowicz E. Chemopreventive and therapeutic affects of trans-resveratrol and its analogues in neoplastic diseases [in Polish]. Pol Merk Lek 2010; 168: 496-500.

[51] Miller NJ, Rice-Evans CA. Antioxidant activity of resveratrol in red wine. Clinical Chemistry. 1995; 41: 1789 .

[52] Min SW, Cho SH, Zhou Y, Schroeder S, Haroutunian V, Seeley WW et al. Acetylation of tau inhibits its degradation and contributes to tauopathy. Neuron. 2010; 67: 953-966.

[53] Min SW, Sohn PD, Cho SH, Swanson RA, Gan L. Sirtuins in neurodegenerative diseases: an update on potential mechanisms. Front Aging Neurosci. 2013; 5: 53.

[54] Mokni M, Elkahoui S, Limam F, Amri M, Aouani E. Effect of Resveratrol on Antioxidant Enzyme Activities in the Brain of Healthy Rat. Neurochemical Research. 2007; 32; 6: 981-987.

[55] Nakagawa T, Lomb DJ, Haigis MC, Guarente L. SIRT5 Deacetylates carbamoyl phosphate synthetase 1 and regulates the urea cycle. Cell. 2009; 137(3): 560-570.

[56] NG F, TANG BL. Sirtuins' modulation of autophagy. J Cell Physiol. 2013; 228(12): 2262-70.

[57] Olas B. Resveratrol as a benefactor in prophylaxis of diseases in circulatory system [in Polish]. Kosmos problemy nauk biologicznych, Polskie Towarzystwo Przyrodników im. Kopernika. 2006; 55, 2-3: 271-272.

[58] Pacholec M, Bleasdale JE, Chrunyk B, Cunningham D, Flynn D, Garofalo RS, Griffith D, Griffor M, Loulakis P, Pabst B, Qiu X, Stockman B, Thanabal V, Varghese A, Ward J, Withka J, Ahn K. SRT1720, SRT2183, SRT1460, and resveratrol are not direct activators of SIRT1. J Biol Chem. 2010; 285(11): 8340-8351. 
[59] Park SJ, Ahmad F, Philp A, Baar K, Williams T, Lou H, Ke H, Rehmann H, Taussig R, Brown, et al. Resveratrol ameliorates aging-related metabolic phenotypes by inhibiting cAMP phosphodiesterases. Cell. 2012; 148: 487-501.

[60] Pope D, Madura JD, Cascio. M. $\beta$-Amyloid and Neprilysin Computational Studies Identify Critical Residues Implicated in Binding Specificity. J. Chem. Inf. Model. 2014.

[61] Qiu X, Brown K, Hirschey MD, Verdin E, Chen D. Calorie restriction reduces oxidative stress by SIRT3-mediated SOD2 activation. Cell Metab. 2010; 12: 662-667.

[62] Quincozes-Santos A, GottrRied C. Resveratrol modulates astroglial functions: neuroprotective hypop thesis. Ann N Y Acad Sci. 2011; 1215: 72-78.

[63] Richard T, Pawlus AD, Iglesias ML, Pedrot E, Waffo-Teguo P,Merillon JM, Monti JP. Neuroprotective properties of resveratrol and derivatives. Ann N Y Acad Sci. 2011; 1215: 103-108.

[64] Riederer BM, Leuba G, Vernay A, Riederer IM. The role of the ubiquitin proteasome system in Alzheimer's disease. Exp Biol Med (Maywood). 2011; 236(3): 268-76.

[65] Robb EL, Page MM, Wiens BE, Stuart JA. Molecular mechanisms of oxidative stress resistance induced by resveratrol: Specific and progressive induction of MnSOD. Biochem. Biophys. Res. Commun. 2008; 367: 406-412.

[66] Rocha KK, Souza GA, Ebaid GX, Seiva FR, Cantaneo AC, Novelli El. Resveratrol toxicity: effects on risk factors for atherosclerosis and hepatic oxidative stress in standard and high-fat diets. Food Chem Toxicol. 2009; 47(6): 1362-1367.

[67] Rodacka A, Strumillo J, Serafin E, Puchala M. Effect of Resveratrol and Tiron on The Inactivation of Glyceraldehyde-3-Phosphate Dehydrogenase Induced by Superoxide Anion Radical. Curr Med Chem. 2014; 21(8):1061-1069.

[68] Rovilllain E, Mansfield L, Caetano C, Alvarez-Fernandez M, Caballero Ol, Medema Rh et al. Activation of nuclear factor-kappaB signalling promotes cellular senescence. Oncogene 2011; 30: 2356-2366.

[69] Ryan MJ, Jackson JR, Hao Y, Williamson CL, Dabkowski ER, Hollander JM, Alway SE. Suppression of oxidative stress by resveratrol after isometric contractions in gastrocnemius muscles of aged mice. J Gerontol A Biol Sci Med Sci. 2010; 65(8): 815-831.

[70] SAUNDERs LR, VERDIN E. Sirtuins: critical regulators at the crossroads between cancer and aging. Oncogene. 2007; 26: 5489-5504.

[71] Scapagnini G, Vasto S, Abraham NG, Caruso C, Zella D, Fabio G. Modulation of Nrf2/ARE pap thway by food polyphenols: a nutritional neuroprotective strategy for cognitive and neurodegenerative disorders. Mol Neurobiol. 2011; 44(2): 192-201.

[72] Seo AY, Joseph AM, Dutta D, Hwang JCY, Aris JP, Leeuwenburgh C. New insights into the role of mitochondria in aging: mitochondrial dynamics and more. J. Cell Sci. 2010; 123: 2533-2542.

[73] Son Y, Lee JH, Chung HT, Pae HO. Therapeutic Roles of Heme Oxygenase-1 in Metabolic Diseases: Curcumin and Resveratrol Analogues as Possible Inducers of Heme Oxygenase-1. Oxid Med Cell Longev. 2013; 639541.

[74] Spanier G, Xu H, Xia N, Tobias S, Deng S, Wojnowski L, Forstermann U, Li H. Resveratrol reduces endothelial oxidative stress by modulating the gene expression of superoxide dismutase 1 (SOD1), glutathione peroxidase 1 (GPx1) and NADPH oxidase subunit (Nox4). J Physiol Pharmacol. 2009; 60(4): 111-116.

[75] StrumilŁo J, Rodacka A, Puchala M. Relationship between structural lack of order and function in inherently unordered proteins [in Polish]. Postępy Biologii Komórki. 2013; 40(4): 602-627.

[76] Sueishi Y, Hori M. Nitric oxide scavenging rates of solubilized resveratrol and flavonoids. Nitric Oxide. 2013; 29: 25-29.

[77] Szewczuk LM, Forti L, Stivalala, Penning TM. Resveratrol is a peroxidase-mediated inactivator of COX-1 but not COX-2: a mechanistic approach to the design of COX-1 selective agents. J Biol Chem. 2004; 279(21): 22727-22737.

[78] Tadolini B, Juliano C, Piu L, Franconi F, Cabrini L. Resveratrol inhibition of lipid peroxidation. Free Radic Res. 2000; 33(1): 105-114. 
[79] Tao R, Coleman MC, Pennington JD, Ozden O, Park SH, Jiang H et al. Sirt3-mediated deacetylation of evolutionarily conserved lysine 122 regulates MnSOD activity in response to stress. Mol.Cell. 2010; 40: 893-904.

[80] Tennen RI, Michishita-Kioi E, Chua KF. Finding a Target for Resveratrol. Cell. 2012; 148, 3: 387-389.

[81] Trela BC, Waterhouse AL. Resver atrol: Isomeric molar absorbivities and stability. J. Agric. Food Chem. 1996; 44: 1253-1257.

[82] Vakhrusheva O, Smolka C, Gajanada P, Kostin S, Boettger T, Kubin T, Braun T, Bober E. Sirt 7 increases stress resistance of cardiomyocytes and prevents apoptosis and inflammatory cardiomyopathy in mice. Circ Res. 2008; 102(6): 703-710.

[83] Van Ham TJ, Thijssen KL, Breitling R, Hofstra RM, Plasterek RH, Nollen EA. C. elegans model identifies genetic modifiers of alpha-synuclein inclusion formation during aging. PLoSGenet. 2008; 4(3): e1000027.

[84] Vang O, Ahmad N, Baile CA, Baur Ja, Brown K, Csiszar A, Das DK, Delmas D, Gottfried C, Lin hy, Ma QY, Mukhopadhyay P, Nalini N, Pezzuto JM, Richard T, Shukla Y, Surh YJ, Szekeres T, Szkudelski T, Walle T, Wu JM. What is new for an old molecule? Systematic review and recommendations on the use of resveratrol. PloS One. 2011; 6(6): 19881.

[85] Vian MA, Tomao V, Gallet S, Coulomb PO, Lacombe JM. Simple and rapid method for cis- and trans-resveratrol and piceid isomers determination in wine by high-performance liquid chromatography using chromolith columns. J Chromatogr A. 2005; 2, 1085(2): 224-229.

[86] Westerheide SD, Anckar J, Stevens SM JR, Sistonen L, Morimoto RI. Stress-inducible regulation of heat shock factor 1 by the deacetylase SIRT1. Science. 2009; 323: 1063-1066.

[87] Wu PF, Xie N, Zhang JJ, Guan XL, Zjou J, Long LH, Li YL, Xiong QJ, Zeng JH, Wang F, Chen JG. Resveratrol preconditioning increases methionine sulfoxide reductases A expression and enhances resistance of human neuroblastoma cells to neurotoxins. J Nutr Biochem. 2013; 24(6): 1070-1077.

[88] YANG J, WANG N, Li J, ZhANG J, FENG P. Effects of resveratrol on NO secretion stimulated by insulin and its dependence on SIRT1 in high glucose cultured endothelial cells. Endocrine. 2010; 37(2): 365-372.

[89] Yeung F, Hoberg JE, Ramsey CS, Keller MD, Jones DR, Frye RA et al. Modulation of NF-kBdependent transcription and cell survival by the SIRT1 deacetylase. EMBO J. 2004; 23: 2369-2380.

[90] Yu LY, Wu ML, Li H, Chen XY, Wang Q, Sun Y, Kong QY, Liu J. Inhibition of STAT3 Expression and Signaling in Resveratrol-Differentiated Medulloblastoma Cells. Neoplasia. 2008; 10(7): 736-744.

[91] Zhong L, D’urso A, Toiber D, Sebastian C, Henry RE, Vaddysirisack DD, Guimaraes A, Marinelli B, Wiksstrom JD, Nir T, Clish CB, Vaitheesvaran B, Iliopoulos O, Kurland I, Dor Y, Weissleder R, Shirihai OS, Ellisen LW, Espinosa JM, Mostoslavsky R. The histone deacetylase Sirt6 regulates glucose homeostasis via Hiflalpha. Cell. 2010; 140(2): 280-293.

Editor-Michat Nowicki

\author{
Joanna Gerszon \\ Department of Radiobiology \\ Faculty of Biology and Environmental Protection \\ University of Łódz \\ Pomorska Street 141/143, 90-236 Eódź \\ e-mail: joanna.gerszon@biol.uni.lodz.pl
}


